\title{
Antibacterial activities of the extracts, fractions and compounds from Dioscorea bulbifera
}

\author{
Victor Kuete ${ }^{1,3^{*}}$, Rémy BetrandTeponno ${ }^{2}$, Armelle Tsafack Mbaveng ${ }^{1}$, Léon Azefack Tapondjou ${ }^{2 *}$, \\ Jacobus J Marion Meyer ${ }^{3}$, Luciano Barboni ${ }^{4}$ and Namrita Lall $^{3}$
}

\begin{abstract}
Background: Dioscorea bulbifera is an African medicinal plant used to treat microbial infections. In the present study, the methanol extract, fractions (DBB1 and DBB2) and six compounds isolated from the bulbils of D. bulbifera, namely bafoudiosbulbins A (1), B (2), C (3), F (4), G (5) and 2,7-dihydroxy-4-methoxyphenanthrene (6), were tested for their antimicrobial activities against Mycobacteria and Gram-negative bacteria involving multidrug resistant (MDR) phenotypes expressing active efflux pumps.
\end{abstract}

Methods: The microplate alamar blue assay (MABA) and the broth microdilution methods were used to determine the minimal inhibitory concentration (MIC) and minimal bactericidal concentration (MBC) of the above samples.

Results: The results of the MIC determinations indicated that when tested alone, the crude extract, fractions DBB1 and DBB2 as well as compounds 2 to 5 were able to prevent the growth of all the fifteen studied microorganisms, within the concentration range of 8 to $256 \mu \mathrm{g} / \mathrm{mL}$. The lowest MIC value for the methanol extract and fractions $(16 \mu \mathrm{g} / \mathrm{mL})$ was obtained with DBB1 and DBB2 on E, coli AG100A and DBB2 on Mycobacterium tuberculosis MTCS2. The lowest value for individual compounds $(8 \mu \mathrm{g} / \mathrm{mL}$ ) was recorded with compound 3 on $\mathrm{M}$. smegmatis and $\mathrm{M}$. tuberculosis ATCC and MTCS2 strains respectively. The activity of the samples on many MDR bacteria such as Enterobacter aerogenes EA289, CM64, Klebsiella pneumoniae KP63 and Pseudomonas aeruginosa PA124 was better than that of chloramphenicol. When tested in the presence of the efflux pump inhibitor against MDR Gram-negative bacteria, the activity of most of the samples increased. MBC values not greater than $512 \mu \mathrm{g} / \mathrm{mL}$ were recorded on all studied microorganisms with fraction DBB2 and compounds 2 to 5 .

Conclusions: The overall results of the present investigation provided evidence that the crude extract $D$. bulbifera as well as some of the compounds and mostly compounds 3 could be considered as potential antimicrobial drugs to fight against MDR bacteria.

Keywords: Diterpenoids, Antimycobacterial, Antibacterial, Dioscorea bulbifera, Dioscoreaceae

\section{Background}

The continuous emergence of Gram-negative MDR bacteria drastically reduces the efficacy of our antibiotic armory and, consequently, increases the frequency of therapeutic failure [1]. On the other hand, the World Health Organization (WHO) estimates that there are nine million cases of tuberculosis (TB) currently, with 1.3 million reported deaths every year, 55 and $30 \%$ of the

\footnotetext{
*Correspondence: Kuetevictor@yahoo.fr; tapondjou2001@yahoo.fr 'Department of Biochemistry, Faculty of Science, University of Dschang, P.O. Box 67, Dschang, Cameroon

${ }^{2}$ Department of Chemistry, Faculty of Science, University of Dschang, Dschang, Cameroon

Full list of author information is available at the end of the article
}

TB burden being shared by Asian and African countries respectively [2]. Approximately $60 \%$ of world's population still relies on medicinal plants for their primary healthcare. Medicinal plants have been used as a source of remedies since ancient times in Africa. Dioscorea bulbifera L. var sativa (Dioscoreaceae) is an African medicinal plant used to treat microbial infections and pig cysticercosis by the native people of western highlands of Cameroon. The plant is also used as a folk remedy to treat conjunctivitis, diarrhea and dysentery, among other ailments [3]. Previous phytochemical study on this medicinal plant led to the isolation and structural elucidation of seven new clerodane diterpenoids namely Bafoudiosbulbins A-G [4-6]. Furthermore, 
the extracts and Bafoudiosbulbins A and B were shown to possess anti-Salmonella activity [4]. In the present study, the bioguided fractionation was undertaken in order to deeply evaluate the antimicrobial activity of D. bulbifera.

\section{Methods}

Plant material

The bulbils of D. bulbifera L. var sativa were collected in Bafou village near Dschang (West region of Cameroon) in February 2007. The plant was identified at the National Herbarium (Yaoundé, Cameroon) where a voucher specimen was deposited under the reference number 22211/SRF/CAM.

\section{Extraction and isolation}

The air-dried bulbils of D. bulbifera $\mathrm{L}$. var sativa $(2 \mathrm{~kg})$ were pulverized and extracted three times (each time for $24 \mathrm{~h}$ ) with $\mathrm{MeOH}$. The methanol extract was concentrated under reduced pressure to yield a dark residue (DBB; $90 \mathrm{~g})$. Part of this $(80 \mathrm{~g})$ was suspended in water $(150 \mathrm{~mL})$ and submitted to successive partition with Ethyl acetate (EtOAc) and $n$-butanol. The EtOAc and $n$-butanol layers were concentrated to dryness under reduced pressure to afford $35 \mathrm{~g}$ and $23 \mathrm{~g}$ of extracts respectively. The $n$-butanol extract showed no antimicrobial activity contrary to the EtOAc extract (Tables 1 and 2). Part of the EtOAc extract (DBB1; $28 \mathrm{~g}$ ) was subjected to column chromatography over silica gel 60 Merck [0.040-0.063 $\mathrm{mm} ; 56 \mathrm{~g}]$ using hexane-EtOAc with increasing polarity as eluents to yield five main sub-fractions named A-E. They were then screened for their antimicrobial activities and sub-Fraction $\mathrm{C}$ (DBB2) eluted with Hexane-EtOAc 4-6 to 3-7 was the only active sample. DBB2 $(\mathrm{m}=4.8 \mathrm{~g})$ was then fractionated and purified using column chromatography over silica gel and sephadex LH-20 to yield compound 1 \{White needles; $[\alpha]_{\mathrm{D}}{ }^{21}=-64.6(\mathrm{c}=0.025$, DMSO); 60 mg; $\mathrm{Rf}=0.78, \mathrm{CH}_{2} \mathrm{Cl}_{2}-\mathrm{MeOH} 95-5 ; \mathrm{C}_{21} \mathrm{H}_{22} \mathrm{O}_{8}$ $m / z 403[\mathrm{M}+\mathrm{H}]^{+}$; m.p. $=252-253^{\circ} \mathrm{C}$ \}, compound 2 \{White needles; $[\alpha]_{\mathrm{D}}{ }^{21}=+52(\mathrm{c}=0.010$, pyridine $) ; 71 \mathrm{mg}$; $\mathrm{Rf}=$ 0.44, $\mathrm{CH}_{2} \mathrm{Cl}_{2}-\mathrm{MeOH} 95-5 ; \mathrm{C}_{20} \mathrm{H}_{20} \mathrm{O}_{8}, m / z 387[\mathrm{M}-\mathrm{H}]^{-} ; \mathrm{m}$. p. $\left.=312-313^{\circ} \mathrm{C}\right\}$, compound 3 \{White gum; $[\alpha]_{\mathrm{D}}^{21}=+56.2^{\circ}$ (c = 0.8, $\mathrm{CH}_{2} \mathrm{Cl}_{2}$ ); $32 \mathrm{mg} ; \mathrm{Rf}=0.37, \mathrm{CH}_{2} \mathrm{Cl}_{2}-\mathrm{MeOH} 95-5$; $\left.\mathrm{C}_{21} \mathrm{H}_{22} \mathrm{O}_{7}, 358[\mathrm{M}-\mathrm{CO}]^{+}\right\}$, compound 4 \{White needles; $[\alpha]$ ${ }_{\mathrm{D}}{ }^{21}=-5^{\mathrm{O}}$ (c = 0.6, $\left.\mathrm{CH}_{2} \mathrm{Cl}_{2}\right) ; 58 \mathrm{mg} ; \mathrm{Rf}=0.56, \mathrm{CH}_{2} \mathrm{Cl}_{2^{-}}$ $\mathrm{MeOH}$ 95-5; $\mathrm{C}_{21} \mathrm{H}_{24} \mathrm{O}_{8} ; m / z 439[\mathrm{M}+\mathrm{Cl}] ;$ m.p. = 265-266 ${ }^{\circ} \mathrm{C}$, compound 5 White crystals; $[\alpha]_{\mathrm{D}}{ }^{20}=-46^{\circ}$ (c = 0.9, $\mathrm{CD}_{3} \mathrm{OD}$ ); $64 \mathrm{mg} ; \mathrm{Rf}=0.41, \mathrm{CH}_{2} \mathrm{Cl}_{2}-\mathrm{MeOH} 95-5$; $\left.\mathrm{C}_{23} \mathrm{H}_{26} \mathrm{O}_{10} ; m / z \quad 485[\mathrm{M}+\mathrm{Na}]^{+} ; \mathrm{m} . \mathrm{p} .=199-200^{\circ} \mathrm{C}\right\}$, compound 6 \{Yellow amorphous powder; $28 \mathrm{mg} ; \mathrm{Rf}=0.48$, $\left.\mathrm{CH}_{2} \mathrm{Cl}_{2}-\mathrm{MeOH} 95-5 ; \mathrm{C}_{15} \mathrm{H}_{12} \mathrm{O}_{3}, m / z 241[\mathrm{M}+\mathrm{H}]^{+}\right\}$.

\section{General procedure}

Melting points were determined using the GallenkampMelting Point Apparatus. Optical rotations were measured on a Perkin-Elmer 241 Polarimeter, IR spectra were measured as a film on a $\mathrm{KBr}$ pellet using a FTIR-8400S Shimadzu spectrometer. ESIMS was carried out on a Hewlett Packard HP-1100 series LCMSD system and on the mass spectrometer Brucker FTMS4.7T, BIOAPEXII. ${ }^{1} \mathrm{H}$ NMR spectra were recorded in deuterated solvents (DMSO and $\mathrm{C}_{5} \mathrm{H}_{5} \mathrm{~N}$ ) on a on a Varian Mercury Plus Spectrometer at $400 \mathrm{MHz}$ while ${ }^{13} \mathrm{C}$ NMR spectra were recorded in the same solvents and the same apparatus at $100 \mathrm{MHz}$. All chemical shifts $(\delta)$ are given in $\mathrm{ppm}$ units with reference to tetramethylsilane (TMS) as internal standard and the coupling constants $(V)$ are in Hz. Column chromatography was performed using silica gel 60 Merck $(0.040-0.063 \mathrm{~mm})$ and sephadex LH-20. TLC were carried out on precoated Kieselgel 60 F254 (Merck) plates developed with hexane:AcOEt (7:3) and AcOEt:MeOH (98:2). TLC plates were viewed with an ultraviolet lamp MULTIBAND UV-254/365 $\mathrm{nm}$ for fluorescent spots. They were also visualized by spraying with $50 \% \mathrm{H}_{2} \mathrm{SO}_{4}$ and heating for $10 \mathrm{~min}$ at $110^{\circ} \mathrm{C}$.

\section{Antimicrobial assays \\ Chemicals for antimicrobial assay}

Chloramphenicol $\geq 98 \%$ (Sigma-Aldrich, St. Quentin Fallavier, France) was used as reference antibiotics (RA) against Gram-negative bacteria. $p$-Iodonitrotetrazolium chloride $\geq 97 \%$ (INT, Sigma-Aldrich) was used as microbial growth indicator $[8,9]$. Ciprofloxacin $\geq 98 \%$ and isoniazid $\geq 99 \%$ (INH) (Sigma) were used as reference antibiotics (RA) for M. smegmatis and M. tuberculosis respectively. Phenylalanine arginine $\beta$-naphthylamide $\geq 98 \%$ (PAßN, Sigma-Aldrich) was used as microbial growth indicator and efflux pumps inhibitor.

\section{Microbial strains and culture media}

The studied microorganisms included strains of Pseudomonas aeruginosa, Klebsiella pneumoniae, Enterobacter aerogenes, Escherichia coli, four Mycobacteria namely $M$. smegmatis, drug-susceptible strain of M. tuberculosis H37Rv obtained from the American Type Culture Collection, and two clinical strains of M. tuberculosis MTCS1, MTCS2. M. smegmatis was cultured on Middlebrook 7H11 agar and allowed to grow for 24 h. M. tuberculosis was plated on LöwensteinJensen medium and allowed to grow for $3-4$ weeks at $37^{\circ} \mathrm{C}$. Middlebrook 7H9 broth was used to determine the MIC and MBC values of the test samples on $M$. smegmatis and $M$. tuberculosis. Nutrient agar was used for the activation of Gram-negative bacteria [10]. The clinical features of the Gram-negative bacteria are available as Additional file 1. 
Table 1 MICs of the extract, fractions, compounds from Dioscorea bulbifera and chloramphenicol on documented strains and clinical MDR isolates Samples $^{\mathrm{a}}$ Microorganisms and MIC $(\mu \mathrm{g} / \mathrm{mL})$ without and in the presence of PAßN (in parenthesis)

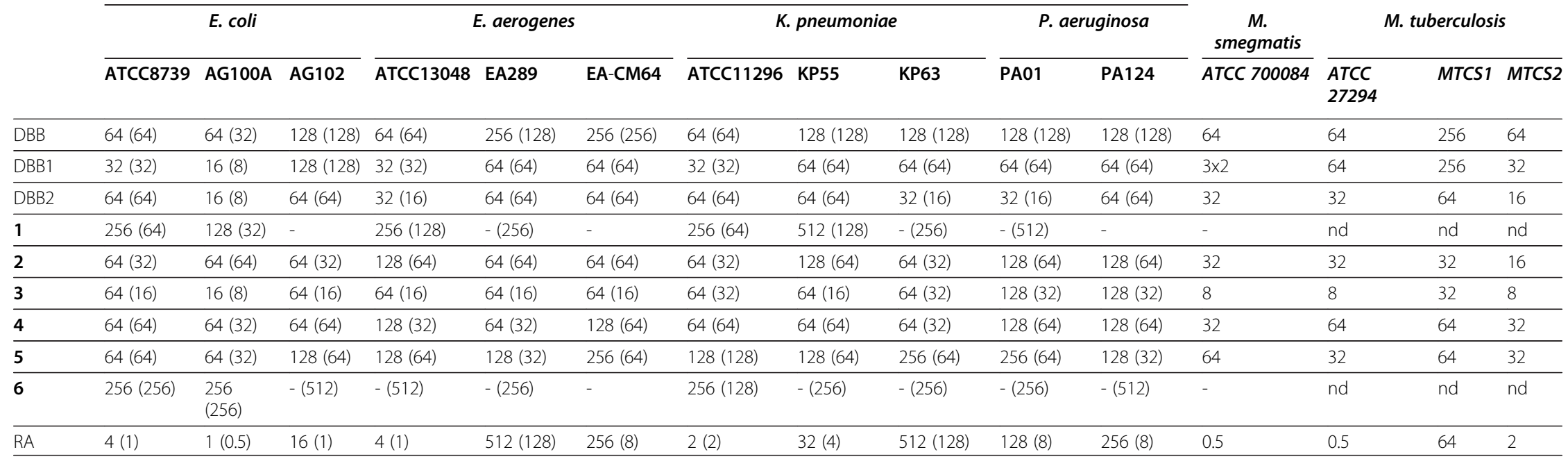

${ }^{\mathrm{a}}$ Tested samples [DBB: methanol extract from the bulbils of D. bulbifera; bafoudiosbulbins A (1), B (2), C (3), F (4), G (5), 2,7-dihydroxy-4-methoxyphenanthrene (6); EtOAc fraction (DBB1) and EtOAc sub-fraction C

(DBB2); RA : reference antibiotics were chloramphenicol for bacteria, ciprofloxacin for M. smegmatis, isoniazid for M.tuberculosis; (-): MIC $>512 \mu \mathrm{g} / \mathrm{mL}$; ${ }^{b}$ The drugs and compounds were tested in the absence or in the presence (values in braket) of PABN at a final concentration of $20 \mathrm{\mu g} / \mathrm{mL}$ as described previously [7]. At this concentration, no intrinsic effect against the various bacterial strains (included as internal controls in each assay without antibiotic) was observed. 
Table 2 MBCs of the extract, fractions, compounds from Dioscorea bulbifera and chloramphenicol on documented strains and clinical MDR isolates Samples Microorganisms and MBC $(\mu \mathrm{g} / \mathrm{mL})$ without and in the presence of PAßN (in parenthesis)

\begin{tabular}{|c|c|c|c|c|c|c|c|c|c|c|c|c|c|c|c|}
\hline & \multicolumn{3}{|c|}{ E. coli } & \multicolumn{3}{|c|}{ E. aerogenes } & \multicolumn{3}{|c|}{ K. pneumoniae } & \multicolumn{2}{|c|}{ P. aeruginosa } & \multirow{2}{*}{$\begin{array}{c}\text { M. } \\
\text { smegmatis } \\
\text { ATCC } \\
700084\end{array}$} & \multicolumn{3}{|c|}{ M. tuberculosis } \\
\hline & ATCC8739 & AG100A & AG102 & ATCC13048 & EA289 & EA-CM64 & ATCC11296 & KP55 & KP63 & PA01 & PA124 & & $\begin{array}{l}\text { ATCC } \\
27294\end{array}$ & MTCS1 & MTCS2 \\
\hline DBB & $128(128)$ & $128(64)$ & $256(256)$ & 128 (128) & $512(512)$ & $-(512)$ & $256(256)$ & $256(256)$ & $256(256)$ & $256(256)$ & $256(256)$ & 128 & 128 & - & 128 \\
\hline DBB1 & $128(64)$ & $32(16)$ & $512(256)$ & $64(64)$ & $128(128)$ & $256(128)$ & $64(64)$ & $128(128)$ & $256(128)$ & $128(128)$ & $128(128)$ & 64 & 128 & - & 64 \\
\hline DBB2 & $256(128)$ & $32(16)$ & $256(128)$ & $64(32)$ & $128(128)$ & $256(128)$ & $128(128)$ & $128(128)$ & $64(64)$ & $64(64)$ & $256(128)$ & 128 & 128 & 128 & 64 \\
\hline 1 & $-(256)$ & 256 (128) & nd & $-(256)$ & nd & nd & - (128) & $-(256)$ & nd & nd & nd & - & nd & nd & nd \\
\hline 2 & $128(128)$ & $128(64)$ & $128(128)$ & $256(128)$ & $128(128)$ & 128 (128) & 128 (128) & $256(128)$ & $128(128)$ & $512(128)$ & $256(128)$ & 64 & 128 & 128 & 64 \\
\hline 3 & $128(32)$ & $128(32)$ & $256(32)$ & $128(32)$ & $256(32)$ & $128(32)$ & $128(64)$ & $128(64)$ & $256(64)$ & $256(64)$ & $256(64)$ & 8 & 16 & 64 & 16 \\
\hline 4 & $128(128)$ & $128(64)$ & $256(128)$ & $256(128)$ & $128(64)$ & $512(128)$ & 256 (128) & $256(128)$ & $128(128)$ & $256(128)$ & $256(128)$ & 64 & 128 & 128 & 128 \\
\hline 5 & $128(128)$ & $128(128)$ & $256(128)$ & $256(128)$ & $256(128)$ & $-(128)$ & $512(256)$ & $512(128)$ & $-(128)$ & $512(256)$ & $512(128)$ & 256 & 128 & 256 & 128 \\
\hline 6 & - & $-(512)$ & - & nd $(-)$ & nd (256) & nd & $-(512)$ & nd (256) & nd (256) & nd (256) & nd (512) & - & nd & nd & nd \\
\hline RA & $8(2)$ & $4(1)$ & $32(2)$ & $8(2)$ & $-(256)$ & $512(16)$ & $4(4)$ & $64(8)$ & $-(256)$ & $256(16)$ & $512(16)$ & 1 & 1 & 128 & 4 \\
\hline
\end{tabular}




\section{INT colorimetric assay for MIC and MBC determinations}

The MIC determinations on M. smegmatis and Gramnegative bacteria were conducted using rapid INT colorimetric assay according to described methods $[8,9]$ with some modifications. The test samples and RA were first of all dissolved in DMSO/Mueller Hinton Broth (MHB) or DMSO/7H9 broth. The final concentration of DMSO was lower than $2.5 \%$ and does not affect the microbial growth [11]. The solution obtained was then added to 7H9 broth (M. smegmatis) or Mueller Hinton Broth (Gram-negative organisms), and serially diluted two fold (in a 96- wells microplate). One hundred microlitre $(100 \mu \mathrm{L})$ of inoculum $1.5 \times 10^{6} \mathrm{CFU} / \mathrm{mL}$ prepared in appropriate broth was then added [12]. The plates were covered with a sterile plate sealer, then agitated to mix the contents of the wells using a plate shaker and incubated at $37^{\circ} \mathrm{C}$ for $18 \mathrm{~h}$. The assay was repeated thrice. Wells containing adequate broth, $100 \mu \mathrm{L}$ of inoculum and DMSO to a final concentration of $2.5 \%$ served as negative control. The MIC of samples was detected after $18 \mathrm{~h}$ incubation at $37^{\circ} \mathrm{C}$, following addition $(40 \mu \mathrm{L})$ of $0.2 \mathrm{mg} / \mathrm{mL}$ $p$-iodonitrotetrazolium chloride (INT) and incubation at $37^{\circ} \mathrm{C}$ for $30 \mathrm{~min}$. Viable bacteria reduced the yellow dye to a pink. MIC was defined as the sample concentration that prevented the color change of the medium and exhibited complete inhibition of microbial growth $[8,9]$. The MBC was determined by adding $50 \mu \mathrm{L}$ aliquots of the preparations, which did not show any growth after incubation during MIC assays, to $150 \mu \mathrm{L}$ of adequate broth. These preparations were incubated at $37^{\circ} \mathrm{C}$ for $48 \mathrm{~h}$. The $\mathrm{MBC}$ was regarded as the lowest concentration of extract, which did not produce a color change after addition of INT as mentioned above $[11,13]$.

Samples were also tested in the presence of PAßN at $30 \mu \mathrm{g} / \mathrm{mL}$ final concentration [7] and the MIC was determined as above.

\section{Time-kill dynamic curves against E. coli ATCC8739}

Time-kill dynamic assay was performed using broth microdilution method as previously described [14] with minor modifications. The final concentration of suspension of the E. coli ATCC8739 strain was adjusted to $10^{6} \mathrm{CFU} / \mathrm{mL}$. The crude extract, fraction DBB2 and compound 3 were used in the time-kill dynamic experiment. Cells treated with concentrations corresponding to $1 / 2 \mathrm{MIC}$; MIC and MBC of each sample were incubated at $37^{\circ} \mathrm{C}$ for $0,30,60,120,240,480$, and $960 \mathrm{~min}$. The final concentration of DMSO was $2.5 \%$. A control sample was made using DMSO 2.5\% and the inoculum. At each incubation time point, liquids $(50 \mu \mathrm{l})$ were removed from the test solution for ten-fold serial dilution. Thereafter, a $25 \mu \mathrm{l}$ liquid from each dilution was spread on the surface of the MHA plates and incubated at $37^{\circ} \mathrm{C}$ for $24 \mathrm{~h}$, and the number of $\mathrm{CFU} / \mathrm{mL}$ was counted. Experiments were carried out in triplicate. Time-kill curves were constructed by plotting the number of $\mathrm{CFU} / \mathrm{mL}$ against time (min).

\section{Microplate Alamar Blue assay against M. tuberculosis}

The activity of all samples against $M$. tuberculosis strains was tested using the MABA [15]. Briefly, each of the above $M$. tuberculosis strains was cultured at $37^{\circ} \mathrm{C}$ in Middlebrook 7H9 broth supplemented with $0.2 \%$ glycerol and 10\% Oleic Acid-Albumin-Dextrose-Catalase (Sigma) until logarithmic growth was reached. About $6 \times 10^{6} \mathrm{CFU} / \mathrm{mL}$ inoculum of $M$. tuberculosis was then added to the two fold serially diluted samples. The final concentration of DMSO in all assays was $2.5 \%$ or less and this dilution also served as solvent control. The samples were assayed in triplicate. All tests were carried out in sterile flat bottom 96-well microplates. Each microplate was incubated for 5 days at $37^{\circ} \mathrm{C}$ in a sealed plastic $\mathrm{CO}_{2}$-permeable bag. After 5 days of incubation, $32 \mu \mathrm{L}$ of a mixture of freshly prepared Alamar Blue solution and $20 \%$ sterile Tween-80 (Sigma) 1:1 v/v were added to one growth-control well. The microplates were incubated again at $37^{\circ} \mathrm{C}$ for $24 \mathrm{~h}$. If a color shift from blue to pink was observed in the growth-control sample, $32 \mu \mathrm{L}$ of alamar blue solution was added to each of the remaining wells, and the microplate was further incubated for $24 \mathrm{~h}$. A well-defined pink color was interpreted as positive bacterial growth, whereas a blue color indicated an absence of growth. The MIC corresponded to the greatest dilution of sample extract in which the color shift from blue to pink was not observed.

Samples with recorded MIC values following MABA were assayed for their mycobactericidal effect [15]. Briefly, $5 \mu \mathrm{L}$ of the undeveloped mycobacterial suspensions were transferred from the former to a new microplate that contained $195 \mu \mathrm{L}$ of fresh culture medium per well. Three wells were inoculated with $100 \mu \mathrm{L}$ of fresh inoculum as for MABA and three more wells were incubated with $200 \mu \mathrm{L}$ of culture medium only, as negative controls. The microplates were incubated and developed with alamar blue as for MABA. The MBC corresponded to the minimum sample concentration that did not cause a color shift in cultures re-incubated in fresh medium.

\section{Results and discussion}

The structural elucidation of the isolated compounds was achieved using physical and spectroscopic techniques as described in our research group. They were identified as diterpenoids bafoudiosbulbins A (1), B (2) [4], C (3) [5], F (4), G (5) [6] and 2,7-dihydroxy-4methoxyphenanthrene (6) [16]. Their chemical structures are illustrated in Figure 1. These compounds 


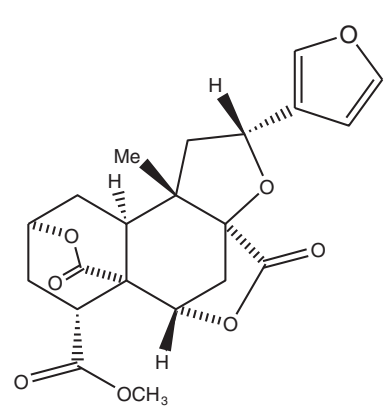

1

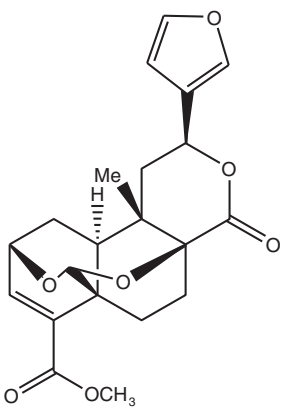

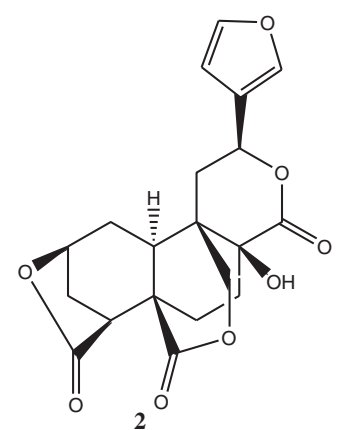
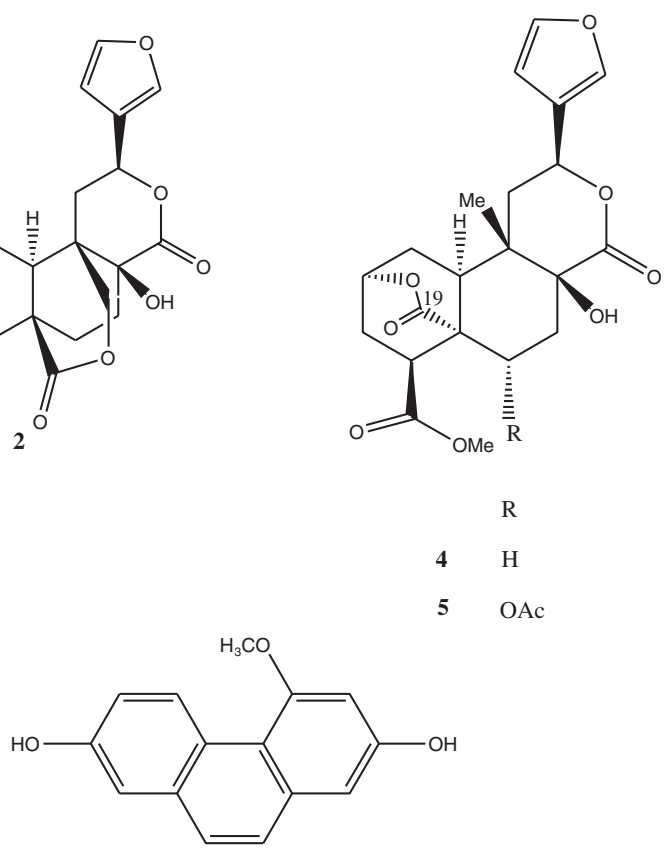

6

Figure 1 Chemical structures of the compounds isolated from the bulbils of Dioscorea bulbifera.

together with the crude extract and fractions were tested for their antimicrobial activities and the results are reported in Tables 1 and 2 .

The results of the MIC determinations (Table 1) indicated that when tested alone, the methanol crude extract, fractions DBB1 and DBB2 as well as compounds $\mathbf{2}$ to $\mathbf{5}$ were able to prevent the growth of all the fifteen studied microorganisms, including mycobacteria and Gramnegative bacteria, within the concentration range of 8 to $256 \mu \mathrm{g} / \mathrm{mL}$. Compounds 1 and $\mathbf{6}$ showed selective activities, their inhibitory effects being noted respectively on $5 / 15$ (33.3\%) and 3/15 (20\%) of the studied microorganisms. The lowest MIC value for the methanol extract and fractions $(16 \mu \mathrm{g} / \mathrm{mL})$ was obtained with DBB1 and DBB2 on E. coli AG100A and DBB2 on M. tuberculosis MTCS2. The lowest value for individual compounds $(8 \mu \mathrm{g} / \mathrm{mL})$ was recorded with compounds 3 on M. smegmatis and M. tuberculosis ATCC and MTCS2 strains. The activity of the samples on many MDR bacteria such as E. aerogenes EA289, CM64, $K$. pneumoniae KP63 and P. aeruginosa PA124 was better than that of chloramphenicol. When tested in the presence of the efflux pump inhibitor against Gram-negative bacteria expression active efflux (Table 1), the activity of most of the samples increased, the lowest MIC values obtained being 8 $\mu \mathrm{g} / \mathrm{mL}$ for DBB1 and 2, compound 3 on E. coli AG100A. Results of MBC determinations (Table 2) also showed good activities for most of the tested samples. When tested in the absence of PAßN, MBC values not greater than $512 \mu \mathrm{g} / \mathrm{mL}$ were recorded on all studied microorganisms with fraction DBB2, compounds 2 to $\mathbf{5}$, on $13 / 15$ (86.7\%) and 14/15 (93.3\%) of the studied organisms respectively the crude extract and fraction DBB1. As previously observed with MIC values, compounds $\mathbf{1}$ and $\mathbf{6}$ showed poor activities in the MBC test. Similarly to MICs data, the MBC values of the samples decrease when they were associated with PAßN. Also, it can be noted (Figure 1) that significant reduction of the bacterial population is observed with the crude extract, fraction DBB2 and compound 3 at a concentration corresponding to their $\mathrm{MBC}$ values.

In the present work, broad spectrum of antimicrobial activities was recorded with the crude extract, fractions and compounds from $D$. bulbifera. Phytochemicals are routinely classified as antimicrobials on the basis of susceptibility tests that produce MIC in the range of 100 to $1000 \mathrm{mg} / \mathrm{mL}$ [17]. Activity is considered to be significant if MIC values are below $100 \mu \mathrm{g} / \mathrm{mL}$ for crude extract and moderate when $100<\mathrm{MIC}<625 \mu \mathrm{g} / \mathrm{mL}[18,19]$. Therefore, the activity recorded with the crude extract on the ATCC strain of E. coli, E. aerogenes, K. pneumoniae, M. smegmatis and M. tuberculosis as well as E. coli AG100A and M. tuberculosis MTCS2, can be considered as important. Similarly, the activity recorded with the two studied fractions from D. bulbifera on the majority of the studied microbial strains was also significant. The activity of compound $\mathbf{3}$ on three of the four tested mycobacterial strains can also be considered good. The MIC values obtained with compound $\mathbf{3}$ on 

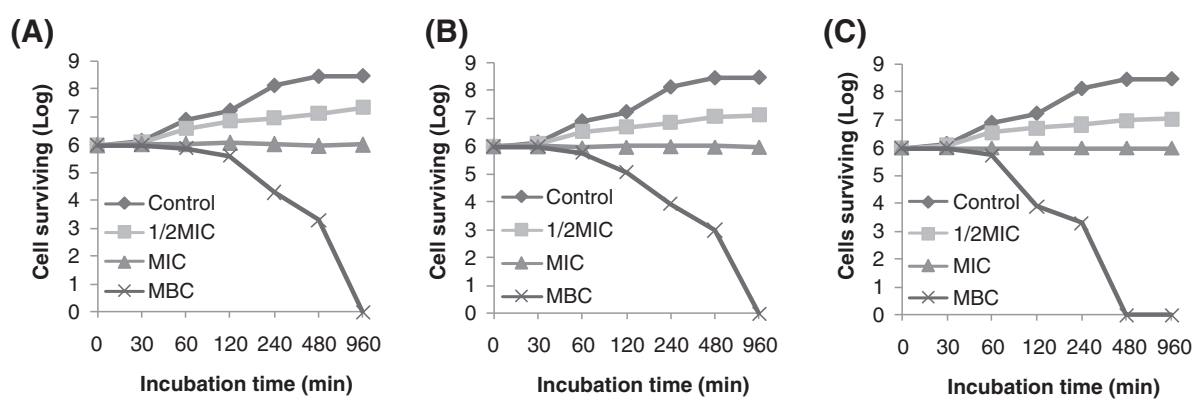

Figure 2 Survival curve for E. coli ATCC8739 cells exposed to the crude extract (A), fraction DBB2 (B) and compound 3 (C). (Control): MHB medium in DMSO $2.5 \%+$ inoculum.

MDR bacteria such as E. aerogenes EA289, CM64, $K$. pneumoniae KP63 and P. aeruginosa PA124 was lower than those of the reference drug, highlighting its good antibacterial potency.

Keen look of the MBC values of the tested samples, alone or in the presence of the efflux pumps inhibitor indicates that most of them are not more than fourfold their corresponding MICs. This proves that the killing effects of many tested samples could be expected on the sensitive strains [20]. This can also be confirmed by the reduction of cell survival at the $M B C$ values of the crude extract, fraction DBB2 and compound 3 as observed in Figure 2. Enterobacteriaceae, including K. pneumoniae, $E$. aerogenes and $E$. coli as well as $P$. aeruginosa and M. tuberculosis have been classified as antimicrobialresistant organisms of concern in healthcare facilities [21-25]. The good activities of the crude extract, fractions and compound 3 on most of the tested microorganisms belonging to MDR phenotypes such as $E$. coli AG102, $P$. aeruginosa PA124, E. aerogenes CM64, K. pneumoniae KP55 and KP63 as observed herein reinforces the hypothesis that $D$. bulbifera can be a potential source of antimicrobial drugs. It should be noted that active compounds from $D$. bulbifera are substrates of MDR bacteria efflux pumps, suggesting a possible use of an inhibitor in the fight against such strains. In this work, only compounds with inhibitory activity on M. smegmatis were tested on M. tuberculosis. However, it has been demonstrated that the sensitivity of M. tuberculosis is closer to that of M. smegmatis, a non pathogenic microorganism [26]. Therefore, this microorganism can be used for a preliminary study to select samples with potential activity against $M$. tuberculosis [26]. Hence, the results obtained herein are in accordance with such recommendation.

To the best of our knowledge, the antimicrobial activities of $D$. Bulbifera against MDR bacteria and mycobacteria strain as well as those of the isolated compounds is being reported for the first time. However the anti-salmonellal activity of compounds $\mathbf{1}$ and $\mathbf{2}$ was reported [4]. Also, a norditerpene, 8-epidiosbulbin E acetate, from Dioscorea bulbifera was found active against MDR Escherichia coli and Pseudomonas aeruginosa with MIC values of 200 and $400 \mu \mathrm{g} / \mathrm{mL}$ respectively [27]. The mechanism of the active compounds is still to be studied; nevertheless, membrane disruption could be suggested as one of the likely mechanisms of action of $\mathbf{1}$ to $\mathbf{5}$, the compounds belonging to the terpenoids [28].

\section{Conclusion}

The data reported herein are very important, taking in account the medical importance of the studied microorganisms. Hence, the overall results of the present investigation provided evidence that the crude extract $D$. bulbifera as well as some of the compounds, and mostly compounds $\mathbf{3}$ could be considered as potential antimicrobial drug.

\section{Additional file}

Additional file 1: Table S1. Gram-negative bacterial strains and features. The studied bacteria included reference ATCC strain of $E$. coli ATCC8739, E. aerogenes ATCC13048, K. pneumoniae ATCC12296 and P. aeruginosa PA01 as well as MDR strains E. coli AG100A and AG102, E. aerogenes EA-CM64 and EA289, K. pneumoniae Kp55 and Kp63, and P. aeruginosa PA124.

\section{Competing interests}

The authors declare that they have no competing interests.

\section{Authors' contributions}

VK, RBT and ATM carried out the study; VK, RBT and ATM wrote the manuscript; VK, LAT, LB, JJMM and NL supervised the work. All authors read and approved the final manuscript.

\section{Acknowledgements}

Authors are thankful to the Cameroon National Herbarium (Yaounde) for the plant identification. Authors are thankful to the Cameroon National Herbarium (Yaounde) for the plant identification. Authors are also grateful to the International Foundation for Science (IFS-Grant F/4579-2) and Organization for the Prohibition of Chemical Weapons (OPCW) through IFS to VK and IFS-Grant F/3976-2 to LAT). Authors are also thankful to UMR-MD1 (Mediterranean University, Marseille, France) for providing some clinical bacteria. 


\section{Author details}

${ }^{1}$ Department of Biochemistry, Faculty of Science, University of Dschang, P.O. Box 67, Dschang, Cameroon. '2Department of Chemistry, Faculty of Science, University of Dschang, Dschang, Cameroon. ${ }^{3}$ Department of Plant Science, Faculty of Agricultural and Biological Science, Pretoria 0002, South Africa. ${ }^{4}$ School of Science and Technology, Chemistry Division, University of Camerino, Via S. Agostino 1, I-62032, Camerino, Italy.

Received: 13 July 2012 Accepted: 16 October 2012

Published: 23 November 2012

\section{References}

1. Rice LB: Unmet medical needs in antibacterial therapy. Biochem Pharmacol 2006, 71:991-995.

2. World Health Organization: Tuberculosis, Fact sheet No. 104. Geneva: World Health Organization; 2010.

3. Duke J: A, DuCellier JL: Handbook of Alternative Cash Crops. Florida: Boca Raton, CRC Press; 1993

4. Teponno RB, Tapondjou AL, Gatsing D, Djoukeng JD, Abou-Mansour E, Tabacchi R, Tane P, Stoekli-Evans H, Lontsi D, Park HJ: Bafoudiosbulbins A and $\mathrm{B}$, two antisalmonellal clerodane diterpenoids from Dioscorea bulbifera var. sativa. Phytochemistry 2006, 67:1957-1963.

5. Teponno RB, Tapondjou AL, Jung HJ, Nam JH, Tane P, Park HJ: Three new clerodane diterpenoids from the bubils of Dioscorea bulbifera var. sativa. Helv Chim Acta 2007, 90:1599-1605.

6. Teponno RB, Tapondjou AL, Abou-Mansour E, Stoeckli-Evans H, Tane P, Barboni L: Bafoudiosbulbins F and G, further clerodane diterpenoids from Dioscorea bulbifera L. var sativa and revised structure of Bafoudiosbulbin B. Phytochemistry 2008, 69:2374-2379.

7. Kuete V, Ngameni B, Tangmouo JG, Bolla J-M, Alibert-Franco S, Ngadjui BT, Pagès J-M: Efflux pumps are involved in the Gram negative bacterial defense against isobavachalcone and diospyrone, two natural products. Antimicrob Agents Chemother 2010, 54:1749-1752.

8. Eloff JN: A sensitive and quick microplate method to determine the minimal inhibitory concentration of plant extracts for bacteria. Planta Med 1998, 64:711-713.

9. Mativandlela SPN, Lall N, Meyer JJM: Antibacterial, antifungal and antitubercular activity of (the roots of) Pelargonium reniforme (CURT) and Pelargonium sidoides (DC) (Geraniaceae) root. S Afr J Bot 2006, 72:232-237.

10. Kuete V, Kamga J, Sandjo LP, Ngameni B, Poumale HM, Ambassa P, Ngadjui BT: Antimicrobial activities of the methanol extract, fractions and compounds from Ficus polita Vahl. (Moraceae). BMC Complement Altern Med 2011, 11:6.

11. Kuete V, Ngameni B, Fotso Simo CC, Kengap Tankeu R, Tchaleu Ngadjui B, Meyer JJM, Lall N, Kuiate JR: Antimicrobial activity of the crude extracts and compounds from Ficus chlamydocarpa and Ficus cordata (Moraceae). J Ethnopharmacol 2008, 120:17-24.

12. Tereschuk ML, Riera MVQ, Castro GR, Abdala LR: Antimicrobial activity of flavonoid from leaves of Tagetes minuta. J Ethnopharmacol 1997, 56:227-232.

13. Zgoda JR, Porter JR: A convenient microdilution method screening natural products against bacteria and fungi. Pharmaceut Biol 2001, 39:221-225.

14. Avila JG, de Liverant JG, Martínez A, Martínez G, Muñoz JL, Arciniegas A, de Vivar AR: Mode of action of Buddleja cordata verbascoside against Staphylococcus aureus. J Ethnopharmacol 1999, 66:75-78.

15. Jimenez-Arellanes A, Meckes M, Ramirez R, Torres J, Luna-Herrera J: Activity against multidrug-resistant Mycobacterium tuberculosis in Mexican plants used to treat respiratory diseases. Phytother Res 2003 17:903-908.

16. Teponno RB, Tapondjou AL, Djoukeng JD, Abou-Mansour E, Tabacchi R, Tane P, Lontsi D, Park HJ: Isolation and NMR assignment of a Pennogenin glycoside from Dioscorea bulbifera var sativa. Nat Prod Sci 2006, 12:62-66.

17. Simões M, Bennett RN, Rosa EA: Understanding antimicrobial activities of phytochemicals against multidrug resistant bacteria and biofilms. Nat Prod Rep 2009, 26:746-757.

18. Kuete V: Potential of Cameroonian plants and derived products against microbial infections: a review. Planta Med 2010, 76:1479-1491.

19. Kuete V, Efferth T: Cameroonian medicinal plants: pharmacology and derived natural products. Front Pharmacol 2010, 1:123.

20. Mims CA, Playfair JHL, Roitt IM, Wakelin D, Williams R: Antimicrobials and chemotherapy. In Med Microbiol Rev. 35th edition. Edited by Mims CA, et al:; 1993:1-34.
21. Nicolle LE: Infection control programmes to contain antimicrobial resistance. WHO/CDS/CSR/DRS/2001.7. http://whqlibdoc.who.int/hq/2001/ WHOCDSCSRDRS2001.7.pdf. Accessed January 2009.

22. Chevalier J, Pagès J-M, Eyraud A, Malléa M: Membrane permeability modifications are involved in antibiotic resistance in Klebsiella pneumoniae. Biochem Biophys Res Commun 2000, 274:496-499.

23. Savafi L, Duran N, Savafi N, Onlen Y, Ocak S: The prevalence and resistance patterns of Pseudomonas aeruginosa in intensive care units in a university hospital. Turk J Med Sci 2005, 35:317-322.

24. Zager EM, McNerney R: Multidrug-resistant tuberculosis. BMC Infect Dis 2008, 8:10

25. Corbett EL, Marston B, Churchyard GJ, De Cock KM: Tuberculosis in subSaharan Africa: opportunities, challenges, and change in the era of antiretroviral treatment. Lancet 2006, 367:926-927.

26. Newton SM, Lau C, Gurcha SS, Besra GS, Wright CW: The evaluation of forty-three plant species for in vitro antimycobacterial activities; isolation of active constituents from Psoralea corylifolia and Sanguinaria Canadensis. J Ethnopharmacol 2002, 79:57-67.

27. Shriram V, Jahagirdar S, Latha C, Kumar V, Puranik V, Rojatkar S, Dhakephalkar PK, Shitole MG: A potential plasmid-curing agent, 8-epidiosbulbin E acetate, from Dioscorea bulbifera L. against multidrugresistant bacteria. Int J Antimicrob Agents 2008, 32:405-410.

28. Cowan MM: Plant products as antimicrobial agents. Clin Microbio/ Rev 1999, 12:564-582.

doi:10.1186/1472-6882-12-228

Cite this article as: Kuete et al.: Antibacterial activities of the extracts, fractions and compounds from Dioscorea bulbifera. BMC Complementary and Alternative Medicine 2012 12:228.

\section{Submit your next manuscript to BioMed Central and take full advantage of:}

- Convenient online submission

- Thorough peer review

- No space constraints or color figure charges

- Immediate publication on acceptance

- Inclusion in PubMed, CAS, Scopus and Google Scholar

- Research which is freely available for redistribution 